\title{
PROGRAMA EDUCAÇÃO CONECTADA: PENSAR A EDUCAÇÃO DO CAMPO EM MEIO A COVID-19'
}

\author{
CONNECTED EDUCATION PROGRAM: THINKING OF \\ FIELD EDUCATION IN THE MIDDLE OF COVID-19
}

\author{
Daniela Camila Froehlich ${ }^{2}$
}

\section{RESUMO}

O presente artigo tem por objetivo abordar o Programa Educação Conectada com o olhar direcionado a Educação do Campo, e o mesmo em meio a COVID-19. Compreendendo que o programa está organizado em três frentes de formação e desenvolve-se em diferentes etapas com a visão de estimular o planejamento da inovação e da tecnologia como elementos transformadores da educação nos estados e municípios, cabe visualizar a Educação do Campo em meio a esse contexto. A análise baseia-se na pesquisa documental, na qual tensiona-se o programa mencionado. As plataformas apresentadas pelo programa são o AVAMEC e o REDMEC, estas responsáveis por recursos educacionais, materiais de formação e cursos de aperfeiçoamento na modalidade a distância. Compreendendo a Educação do Campo e como é pensado o contexto educacional para o mesmo, trago análises para que os profissionais, e sujeitos, que estudem essa modalidade se ocupem a pensar e questionar as condições de ensino-aprendizagem consideradas por meio deste programa, principalmente no contexto atual que está sendo vivenciado.

Palavras-chave: Educação, Pandemia, Formação.

\section{ABSTRACT}

This article aims to approach the Connected Education Program with a focus on Countryside Education, and the same in the midst of COVID-19. Understanding that the program is organized in three training fronts and develops in different stages with the vision of stimulating the planning of innovation and technology as transforming elements of education in the states and municipalities, it is necessary to visualize the Education of the Countryside in the midst of this In this context. The analysis is based on documentary research, in which the mentioned program is tensioned. The platforms presented by the program are AVAMEC and REDMEC, which are responsible for educational resources, training materials and training courses in distance learning. Understanding the Education of the Countryside and how the educational context is thought for, I bring analyzes so that professionals, and subjects, who study this modality are busy thinking and questioning the teachinglearning conditions considered through this program, mainly in current context that is being experienced.

Keywords: Education, Pandemy, Formation.

\footnotetext{
${ }^{1}$ Pesquisa referente à COVID-19.

${ }^{2}$ Mestranda em Geografia pelo Programa de Pós-graduação em Geografia da Universidade Federal de Santa Maria (UFSM). E-mail: danielacfroehlich@hotmail.com
} 


\section{INTRODUÇÃO}

Esta escrita tem por intuito abordar o Programa Educação Conectada, criado no ano de 2017 pelo Ministério da Educação, para assim pensar e tensionar a Educação do Campo, permeada neste contexto, e como a mesma vem sendo apresenta por este programa considerando a situação de pandemia vigente em 2020 (COVID-19).

A Educação do Campo, aquela voltada a atender as demandas dos sujeitos do campo, pensada em estratégias que ajudem a reafirmar identidades do campo, vem sendo contemplada nas estratégias atuais voltadas a educação? Devido a essa situação vivida, de distanciamento social, cabe aqui tensionarmos quais possibilidades surgem a esta modalidade, como suprir a demanda educacional em tempos de pandemia, e assim, quais os programas que surgem para isso, e se eles atendem essas necessidades.

A pesquisa é uma análise documental exploratória, na qual foi desenvolvida em plataformas digitais, sendo elas o do Programa Educação Conectada em sua integra, posterior a plataforma digital do REDMEC, e por final a AVAMEC. A estruturação desta análise e a interlocução com a Educação do Campo e o contexto pandêmico, faz-se no decorrer dos tensionamentos.

$\mathrm{O}$ artigo encontra-se organizado em algumas sessões para dar seguimento a escrita, atingindo seus objetivos e percurso metodológico, sendo o primeiro tópico denominado Programa Educação Conectada, o seguinte Educação do Campo, posteriormente o Desenvolvimento, o qual aborda os subtópicos REDMEC e AVAMEC, e por fim, os Resultados e Discussões, e a Conclusão, os quais não tem por intuito trazer verdades absolutas, mas sim instigar olhares e questionamentos dos sujeitos que trabalham com a temática.

\section{Programa Educação Conectada}

Para iniciar essa análise considero relevante o conhecimento dos elementos que serão abordados, como o Programa Educação Conectada e suas plataformas, como também da Educação do Campo, da condição de isolamento social e educação a distância, devido ao quadro de doenças provocada pelo Coronavírus, que são o alicerce desta análise.

O programa Educação Conectada foi instituído pelo decreto $n^{\circ} 9.204$, de 23 de novembro de 2017, com o objetivo da universalização do acesso à internet de alta velocidade e fomentar o uso pedagógico de tecnologias digitais na Educação Básica.

O PRESIDENTE DA REPÚBLICA, no uso da atribuição que lhe confere o art. 84, caput, incisos IV e VI, alínea "a", da Constituição, e tendo em vista o disposto no art. 24, caput, incisos I e VIII, da Lei ${ }^{\circ}$ 12.965, de 23 de abril de 2014, decreta: Art. $1^{\circ}$ - Fica instituído o Programa de Inovação Educação Conectada, em consonância com a estratégia 7.15 do Plano Nacional de Educação, aprovado pela Lei n ${ }^{\circ} 13.005$, de 25 de junho de 2014, com o objetivo de apoiar a universalização do acesso à internet em alta velocidade e fomentar o uso pedagógico de tecnologias digitais na educação básica. (BRASIL, 2017). 
O mesmo foi dividido em três fases para sua implementação sendo elas: (1) indução (2017 a 2018) para construção e implantação do Programa com metas estabelecidas para alcançar o atendimento de 44,6\% dos alunos da educação básica; (2) expansão (2019 a 2021) com a ampliação da meta para 85\% dos alunos da educação básica e início da avaliação dos resultados; e (3) sustentabilidade (2022 a 2024) com o alcance de 100\% dos alunos da educação básica, transformando o Programa em Política Pública de Inovação e Educação Conectada. Na Figura 1, pode ser visualizada a página online do programa, a qual encaminha o acesso as demais plataformas.

Figura 1 - Página Inicial do Programa Educação Conectada.

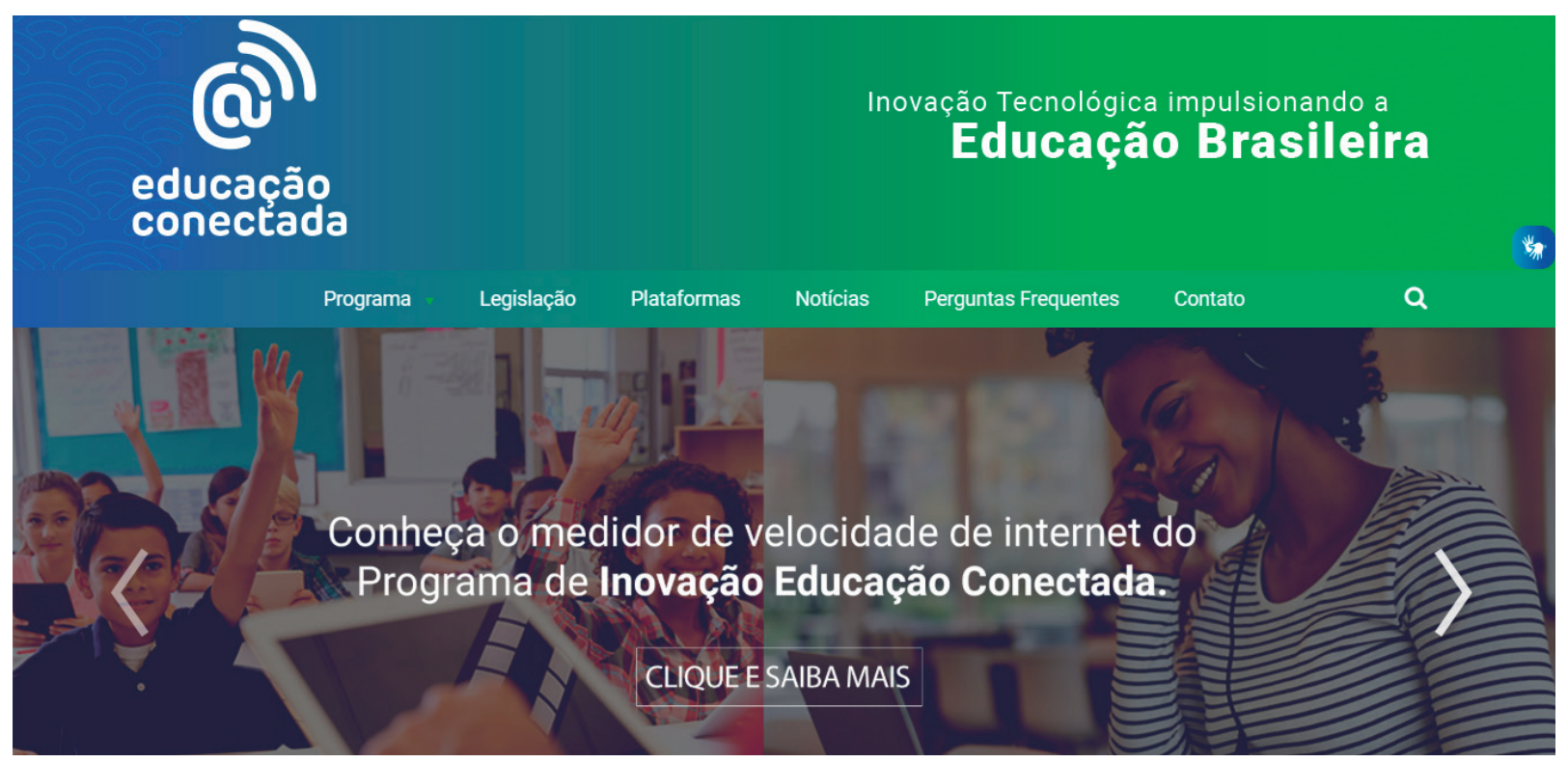

Fonte: Programa Educação Conectada. Disponível em: http://educacaoconectada.mec.gov.br/

Abordar esse programa requer compreendê-lo e também analisá-lo para, assim, visualizar se o mesmo contempla a realidade das escolas do campo e como o mesmo se articula nos tempos de pandemia.

Para esta escrita foi realizada uma análise no site do Ministério da Educação referente ao programa, como em suas plataformas AVAMEC e REDMEC. Para abordar as plataformas, cabe aqui conhecê-las, a plataforma AVAMEC, segundo o Ministério da Educação (2017, p. 1).

[...] é um ambiente virtual colaborativo de aprendizagem que permite a concepção, administração e desenvolvimento de diversos tipos de ações formativas, como cursos à distância, complemento a cursos presenciais, projetos de pesquisa, projetos colaborativos e diversas outras formas de apoio educacional à distância ao processo ensino-aprendizagem.

Já a Plataforma REDMEC

A partir de uma iniciativa do Ministério da Educação, surge em outubro de 2015 a proposta de reunir e disponibilizar, em um único lugar, os Recursos Educacionais Digitais dos principais portais do Brasil. Com o objetivo de melhorar a experiência de busca desses Recursos, 
a Plataforma foi desenvolvida numa parceria coletiva entre: Universidade Federal de Santa Catarina (UFSC), Universidade Federal do Paraná (UFPR) e professoras(es) da Educação Básica de todo o Brasil. Assim, a Plataforma MEC pretende se tornar uma referência em Recursos Educacionais Digitais, como um ambiente de busca, interação e colaboração entre professoras(es). (BRASIL, 2017, p. 1).

Pensar esse programa, com suas plataformas, torna-se relevante, considerando o período pandêmico que estamos passando devido a doença coronavírus (COVID-19), a qual requer o isolamento social, e assim, o aumento/condicionamento do uso de ambientes/plataformas digitais, as quais acabam ocupando lugar chefe no espaço educacional.

Trazendo a Educação do Campo pra esse contexto, é importante considerar que a mesma

[...] nasceu como mobilização/pressão de movimentos sociais por uma política educacional para comunidades camponesas: nasceu da combinação das lutas dos Sem Terra pela implantação de escolas públicas nas áreas de Reforma Agrária com as lutas de resistência de inúmeras organizações e comunidades camponesas para não perder suas escolas, suas experiências de educação, suas comunidades, seu território, sua identidade (CALDART, 2012, p. 15).

Com isso, visualizar e analisar se essa plataforma que está sendo implantada em âmbito nacional supre essas demandas condiciona nossas aprendizagens do presente momento como também as posteriores, como pode ser visto em suas etapas de implantação. Assim, para essa análise, trago conceituações acerca da Educação do Campo, o que possibilitara essas observações.

\section{Educação do Campo}

A Educação do Campo é permeada por marcos históricos de luta e resistência por um longo período, para conseguir seu reconhecimento e manter-se viva. Uma população que ficou por muitos anos esquecida, como reflete Leite (1999, p. 28),

[...] A sociedade brasileira somente despertou para a educação rural por ocasião do forte movimento migratório interno dos anos 1910-1920, quando um grande número de rurícolas deixou o campo em busca das áreas onde iniciava um processo de industrialização mais amplo.

Mesmo o Brasil sendo um país agrário, só foi contemplar nas políticas públicas a educação rural no ano de 1934, sequer mencionava acerca da educação rural em seus textos constitucionais de 1824 e 1891, o que evidencia dois problemas de governança pública a saber: o descaso por parte dos dirigentes com a educação destinada aos camponeses e resquícios de uma cultura política fortemente alicerçada numa economia agrária com base no latifúndio e no trabalho escravo. (NASCIMENTO, 2009, p. 160).

Nas primeiras décadas do século XX aparecem os primeiros movimentos direcionados ao surgimento de incentivos preparatórios para o campo, marcados por concepções e práticas neoliberais inculcadas pelo gerencialismo. Pode se considerar que as três últimas décadas do século XX 
representam um período de movimentação e organização por parte dos agricultores e suas entidades, não mais por uma educação rural, mas uma educação do campo, o que demonstra a eficácia dos discursos produzidos na constituição de sujeitos que assumem a necessidade de estar, permanecer e qualificar a vida no campo para conquistar melhores condições de participação nas tramas da economia, tudo isso operando a partir do investimento na escola.

De acordo Roseli Caldart (2002), em 1997, no primeiro encontro Nacional dos educadores e educadoras da Reforma Agrária (ENERA), realizado pelo Movimento dos Trabalhadores Sem Terra - MST, foram levantadas questões sobre uma série de questões sobre a educação no meio rural brasileiro. Era a primeira vez que se discutia de forma ampla a educação no espaço rural brasileiro. Segundo a autora nas discussões de preparação do documento base da I Conferencia concluído em 1998 explicita-se o contraponto que se pretende fazer com a chamada educação rural. Passa-se a utilizar a expressão campo e não mais meio rural, com o objetivo de incluir as lutas sociais e culturais dos camponeses.

O surgimento da expressão "Educação do Campo" pode ser datado. Nasceu primeiro como Educação Básica do Campo no contexto de preparação da I Conferência Nacional por uma Educação Básica do Campo, realizada em Luziânia, Goiás, de 27 a 30 de julho 1998. Passou a ser chamada Educação do Campo a partir das discussões do Seminário Nacional realizado em Brasília de 26 a 29 de novembro 2002, decisão posteriormente reafirmada nos debates da II Conferência Nacional, realizada em julho de 2004. (CALDART, 2012, p. 260)

Os protagonistas do processo de criação da Educação do campo são os 'movimentos sociais camponeses em estado de luta', com destaque aos movimentos sociais de luta pela reforma agrária e particularmente ao MST. O vínculo de origem da Educação do campo é com os trabalhadores 'pobres do campo', trabalhadores sem-terra, sem trabalho, mas primeiro com aqueles já dispostos a reagir, a lutar, a se organizar contra 'o estado da coisa', para aos poucos buscar ampliar o olhar para o conjunto dos trabalhadores do campo". (CALDART,2009 p. 41)

Os propósitos deste movimento que vem buscando compreender a educação do campo no país, problematizando as diversas realidades e buscando alternativas é definido por Caldart (2002) como

Um dos traços fundamentais que vêm desenhando a identidade deste movimento por uma educação do campo é a luta do povo do campo por políticas públicas que garantam o seu direito à educação, e a uma educação que seja no e do campo. No: o povo tem direito a ser educado no lugar onde vive; Do: o povo tem direito a uma educação pensada desde o seu lugar e com a sua participação, vinculada à sua cultura e às suas necessidades humanas e sociais (CALDART, 2002, p. 18).

Diversos teóricos, por meio de seus estudos, têm trazido contribuições para o reconhecimento da Educação do Campo, pensando em uma educação que traga a autonomia dos sujeitos e o protagonismo das escolas do campo. 
A partir de políticas públicas abrangentes, passa-se ao longo do tempo a elaborar-se políticas direcionadas aos sujeitos do campo. Diferentes Políticas foram elaboradas para defender os direitos dos camponeses, visando uma educação que suprisse a necessidade daquele povo, com isso atualmente encontramos políticas regentes voltadas especificamente as pessoas do campo, entretanto apesar desse aumento de direitos, sabemos que as mesmas ainda sofrem discriminação nos dias de hoje.

Compreendendo assim, qual o olhar abordado sobre a Educação do Campo, torna-se possível apresentar o programa e suas plataformas, e as proposições, a quais apareceram neste decorrer.

\section{Plataformas Executivas do Programa Educação Conectada}

Conhecer as plataformas, suas estruturas, objetivos, finalidades e a quem é direcionado é relevante para pensar a Educação do Campo, o ensino a distância juntamente com a condição de isolamento social do presente momento. Organizo essas analises trazendo inicialmente a plataforma REDMEC, posterior o AVAMEC, na sequencia compreensões sobre a Educação do Campo e a pandemia juntamente com o ensino a distância (online).

\section{REDMEC}

Na plataforma Recursos Educacionais Digitais (REDMEC) encontram-se materiais de formação, alguns cursos oferecidos pelo MEC e seus parceiros. As ofertas dos materiais são divididas em três abas, sendo elas a de Recursos Educacionais Digitais, Materiais de Formação e Coleções dos Usuários. A página inicial da plataforma pode ser visualizada na figura 2.

Figura 2 - Página Inicial REDMEC

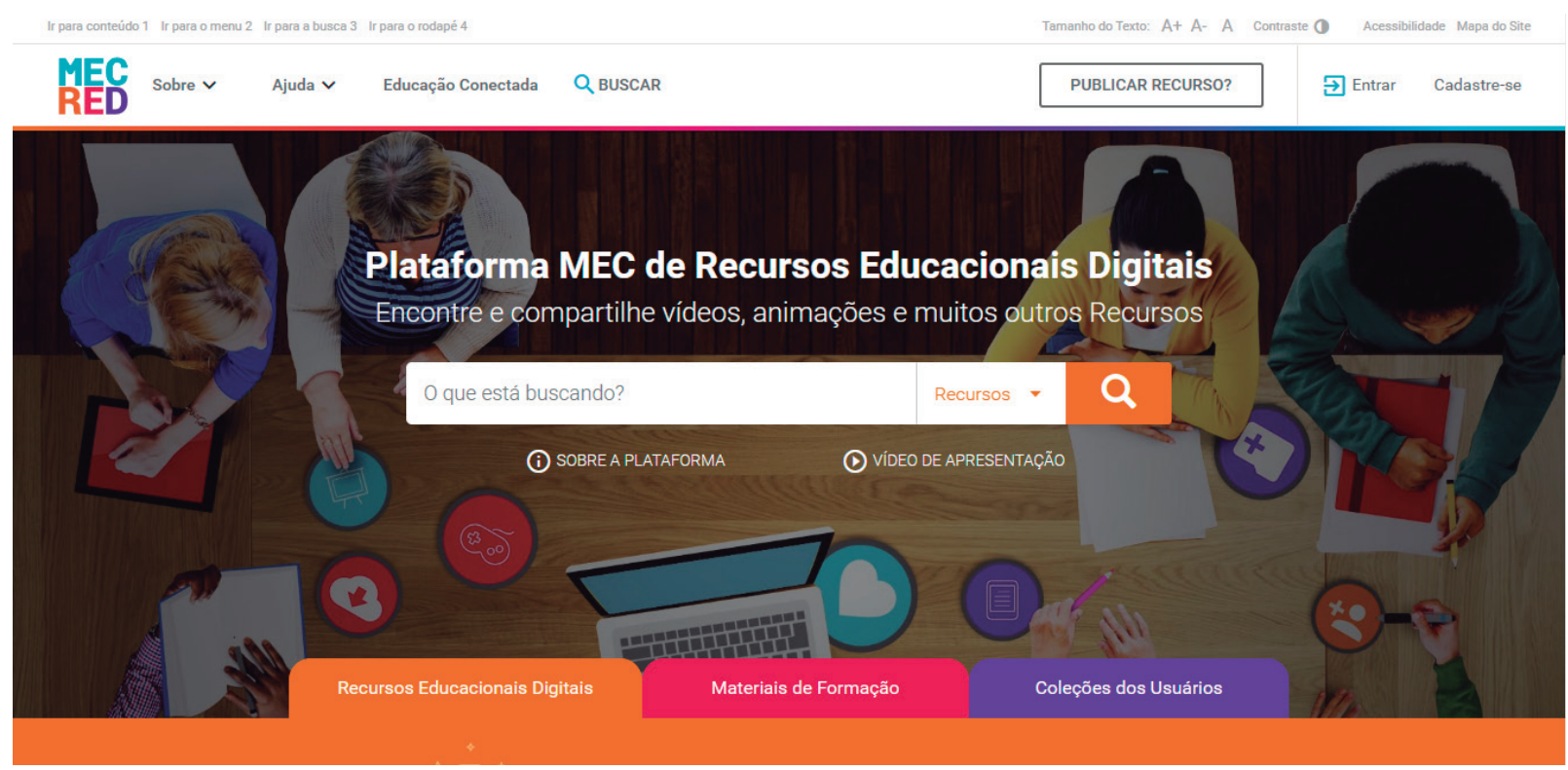

Fonte: REDMEC. Disponível em: https://plataformaintegrada.mec.gov.br/home 
Analisando a plataforma, adentrando na aba Recursos Educacionais Digitais são encontrados 321327 recursos disponíveis, dentre vídeos, livros digitais, áudio, imagem, jogos, textos, experimentos práticos, infográficos, mapas, animação, apresentação, plano de aula e software educacional e website externo, e nestes apenas um artigo, dentre os milhares de materiais indicados para a formação aborda a Educação do Campo, sendo ele Práticas Educativas Comparadas em Educação do Campo e os Desafios da Formação Omnilateral na América Latina, com autoria de Fábio Fernandes Villela.

$\mathrm{Na}$ aba Materiais de Formação, encontram-se 4 volumes, que variam de quatro a vinte e nove módulos, com diversas temáticas, mas novamente nenhuma direcionada a Educação do Campo. Analisando a última aba, Coleções dos Usuários, apresenta 814 coleções encontradas, e dessas nenhuma direcionada a Educação do Campo. Seguindo a análise do programa, na sequência a outra plataforma, AVAMEC, observando suas ofertas e materiais oferecidos, visualizando as áreas atendidas.

\section{AVAMEC}

O Ambiente Virtual colaborativo de Aprendizagem (AVAMEC), sendo um ambiente formador, conta com parceria de diferentes instituições para possibilitar a oferta de vários cursos a comunidade, sendo elas a Universidade Federal de Goiás (UFG), Universidade Federal de Alagoas (UFAL), Secretaria de Educação de São Bernardo dos Campos, MEC (Secretaria de Educação Básica - Superior -Alfabetização), Programa Impulsiona Instituto Península, Coordenadoria de Aperfeiçoamento de Pessoal de Nível Superior (Capes) e a Controladoria Geral da União.

A seguir pode ser visualizado a entrada principal da plataforma de acesso aos cursos ofertados (figura 3).

Figura 3 - Página Inicial AVAMEC

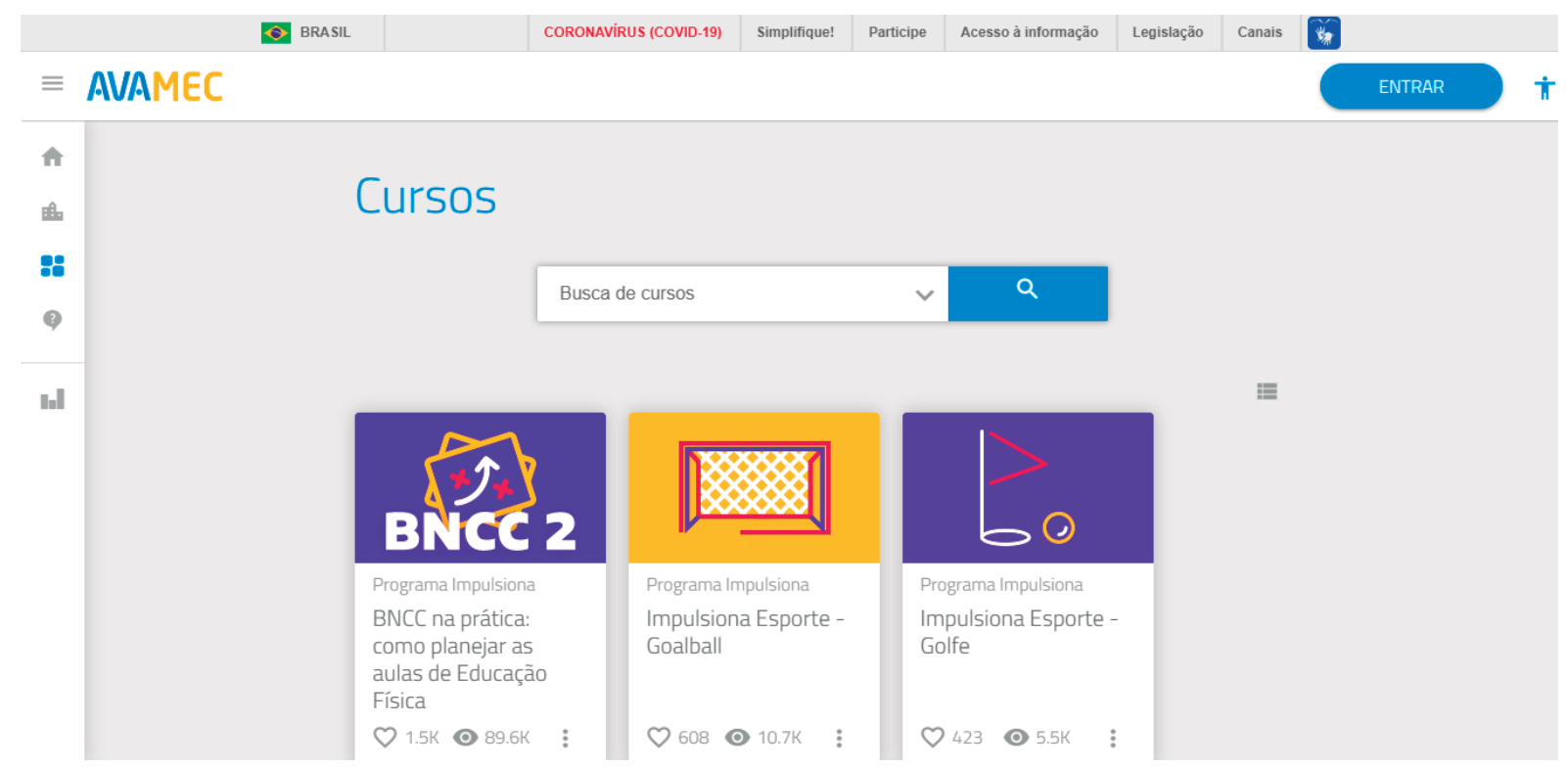

Fonte: AVAMEC. Disponível em: https://avamec.mec.gov.br/\#/ 
Dentre os 98 cursos de formação oferecidos na plataforma AVAMEC nenhum deles direciona-se a Educação do Campo, os cursos apresentados podem ser vistos no quadro 1.

Quadro 1 - Cursos oferecidos.

\begin{tabular}{|c|c|}
\hline \multicolumn{2}{|r|}{ Cursos } \\
\hline 1 & BNCC na prática: como planejar as aulas de Educação Física \\
\hline 2 & Impulsiona Esporte - Goalball \\
\hline 3 & Impulsiona Esporte-Golfe \\
\hline 4 & A BNCC do Ensino Médio: Ciências Humanas \\
\hline 5 & A BNCC do Ensino Médio: Ciências da Natureza \\
\hline 6 & A BNCC do Ensino Médio: Linguagens e suas Tecnologias \\
\hline 7 & A BNCC do Ensino Médio: Matemática e suas Tecnologias \\
\hline 8 & A BNCC e a Gestão Escolar \\
\hline 9 & A BNCC na Educação Infantil \\
\hline 10 & A BNCC nos Anos Finais do Ensino Fundamental: Arte \\
\hline 11 & A BNCC nos Anos Finais do Ensino Fundamental: Ciências \\
\hline 12 & A BNCC nos Anos Finais do Ensino Fundamental: Educação Física \\
\hline 13 & A BNCC nos Anos Finais do Ensino Fundamental: Ensino Religioso \\
\hline 14 & A BNCC nos Anos Finais do Ensino Fundamental: Geografia \\
\hline 15 & A BNCC nos Anos Finais do Ensino Fundamental: História \\
\hline 16 & A BNCC nos Anos Finais do Ensino Fundamental: Língua Inglesa \\
\hline 17 & A BNCC nos Anos Finais do Ensino Fundamental: Língua Portuguesa \\
\hline 18 & A BNCC nos Anos Finais do Ensino Fundamental: Matemática \\
\hline 19 & A BNCC nos Anos Iniciais do Ensino Fundamental \\
\hline 20 & A importância de analisar a qualidade da internet \\
\hline 21 & Aperfeiçoamento em Conselho Escolar \\
\hline 22 & Aplicações do Pensamento Computacional para os Anos Finais do Ensino Fundamental \\
\hline 23 & Aplicações do Pensamento Computacional para os Anis Iniciais do Ensino fundamental \\
\hline 24 & Atletismo na Escola \\
\hline 25 & Atualiza COVID-19 \\
\hline 26 & Tecnologias Educacionais \\
\hline 27 & A BNCC na prática: do currículo a sala de aula Desvendando as Diretrizes para a Educação Física \\
\hline 28 & Capacitação LabTIME \\
\hline 29 & Capacitação para Conselheiros de Políticas Públicas \\
\hline 30 & Competências Socioemocionais na Educação Esportiva \\
\hline 31 & Conectar e Incluir \\
\hline 32 & Conectar, Educar e Cuidar \\
\hline 33 & Conselheiros Escolares \\
\hline 34 & Controle Social e Cidadania \\
\hline 35 & Programação e Robótica \\
\hline 36 & Dados Abertos \\
\hline 37 & Educação de Jovens e Adultos \\
\hline 38 & Educar e Cuidar \\
\hline 39 & Educação Cidadã - Ética, cidadania e o combate a corrupção \\
\hline 40 & Educação Inclusiva \\
\hline 41 & Educação e Ciberespaço \\
\hline 42 & Ciências Humanas - 1 \\
\hline 43 & Ciências Humanas - 2 \\
\hline 44 & Ciências Humanas - 3 \\
\hline 45 & Ciências da Natureza - 1 \\
\hline 46 & Ciências da Natureza - 2 \\
\hline 47 & Ciências da Natureza - 3 \\
\hline
\end{tabular}




\begin{tabular}{|c|c|}
\hline 48 & Linguagens - 1 \\
\hline 49 & Linguagens - 2 \\
\hline 50 & Linguagens - 3 \\
\hline 51 & Matemática - 1 \\
\hline 52 & Matemática - 2 \\
\hline 53 & Matemática - 3 \\
\hline 54 & Escola da Infância - Creches Parceiras \\
\hline 55 & Escola da Infância - 2020- Aulas 1 e 2 \\
\hline 56 & Escola da Infância- Creche \\
\hline 57 & Escola da Infância - Pré Escola \\
\hline 58 & Escola da Infância - Mod. II \\
\hline 59 & Professores e coordenadores \\
\hline 60 & Professores e Coordenadores- EJA \\
\hline 61 & PAPP TEC \\
\hline 62 & Práticas de Alfabetização \\
\hline 63 & Formação do Programa Inovação Educação Conectada \\
\hline 64 & Governo Aberto \\
\hline 65 & Impulsiona Esporte - Esporte Orientação \\
\hline 66 & Impulsiona Esporte - Futebol de 5 \\
\hline 67 & Impulsiona Esporte - Ginástica Artística \\
\hline 68 & Impulsiona Esporte - Hóquei sobre grama \\
\hline 69 & Impulsiona Esporte - Mini atletismo \\
\hline 70 & Impulsiona Esporte - Rugby \\
\hline 71 & Impulsionador Esportivo \\
\hline 72 & Impulsionador Estratégico \\
\hline 73 & Instrumentos de controle social e cidadania - Como exercer seus direitos? \\
\hline 74 & Introdução ao Pensamento Computacional \\
\hline 75 & Leitura Conectada \\
\hline 76 & Matemática \\
\hline 77 & Matemática 2020 \\
\hline 78 & Matemática II \\
\hline 79 & Metodologias Ativas na Educação Física \\
\hline 80 & Movimento Paralímpico: fundamentos básicos do esporte \\
\hline 81 & MAAv - Português e Saúde em Movimento \\
\hline 82 & MAAv - Saúde \\
\hline 83 & Orientador de Alunos Líderes \\
\hline 84 & Os Conselhos de Educação e a Implementação da BNCC \\
\hline 85 & Orientadores Pedagógicos \\
\hline 86 & Participação Social e a atuação dos gestores públicos \\
\hline 87 & Português \\
\hline 88 & Português 2020 \\
\hline 89 & Recursos Digitais - Gestores (INFANTIL) \\
\hline 90 & Recursos Digitais - Gestores PAPP (FUN e EJA) \\
\hline 91 & Recursos Digitais - Professores \\
\hline 92 & Recursos Digitais - Professores Creche \\
\hline 93 & Capacitação ECIM \\
\hline 94 & TICs \\
\hline 95 & TICs 2020 \\
\hline 96 & TICS \\
\hline 97 & Transparência Pública: Regulamentação da LAI e Portais de Transparência \\
\hline 98 & Ética na Administração Pública \\
\hline
\end{tabular}

Fonte: Elaboração Própria com base nos dados da Plataforma Educação Conectada.

Disponível em: http://educacaoconectada.mec.gov.br/. 
Os cursos ofertados configuram-se em quatro categorias, sendo elas aperfeiçoamento, capacitação, especialização e extensão, mas destes apenas estão disponíveis na plataforma as de aperfeiçoamento e capacitação, com duração que variam de $20 \mathrm{~h}$ a $40 \mathrm{~h}$ de aperfeiçoamento, comprovados por meio de certificação digital. Os mesmos são destinados as seguintes etapas: Educação Infantil, Ensino Fundamental e Ensino Médio, abordando os seguintes componentes curriculares: Artes, Biologia, Ciências, Educação Física, Ensino Religioso, Filosofia, Física, Língua Espanhola, Língua Inglesa, Língua Portuguesa, Matemática, Outras Línguas, Química e Sociologia.

Dentro de uma abordagem geral, as escolas do campo trabalham os componentes curriculares, mas com suas próprias especificidades, atendendo as demandas dos sujeitos do campo, no qual esses componentes tem de ser integrados a realidade do campo, com isso, analisando os cursos ofertados, visualiza-se que os mesmo não buscam trabalhar essa aproximação com essa realidade, não trazendo subsídios de aperfeiçoamento a estes professores que atuam junto a essas escolas.

Nos cursos ofertados para formação dos articuladores do programa, pode ser visualizado que não apresenta nenhum curso específico voltado a atender a Educação do Campo, que vá atender as demandas dos formadores, como também dos sujeitos do campo, que também serão permeados por este.

\section{RESULTADOS E DISCUSSÕES}

Visualizando a análise abordada referente ao programa e suas plataformas, considerando a Educação do Campo e o momento pandêmico a qual estamos passando, cabe trazer aqui alguns tensionamentos.

A pandemia do COVID-19, a qual está modificando os tipos de relações que estabelecemos e como essas se dão, sendo elas no contexto social, educacional, familiar, religioso, dentre outros, nos leva a busca de novos meios de possibilitar que estes sejam realizados, não mais prioritariamente pelo contato e modo presencial, como anteriormente. Assim, o meio remoto, digital, passa a ocupar papel principal nesses contatos e mediações, o que interfere diretamente no contexto escolar/educacional, que o qual está em pauta nesta escrita.

Quando se analisa um programa digital que proporciona plataformas de profissionalização, formação, a distância, considerando o presente momento, torna-se relevante, e principalmente quando voltarmos nosso olhar a Educação do Campo, como a mesma está ocorrendo e como este programa pode ou não estar atendendo as demandas dessa modalidade de ensino.

Assim, a análise cunha um viés reflexivo, para que em meio a diversos debates, discussões envolvendo a Educação do Campo, o contexto atual e as plataformas de formação e capacitação, possamos tensionar as possibilidades que são tidas para essa educação e fazer com que as pessoas que se ocupam da área possam pensar novas possibilidades e questionamentos. 


\section{CONCLUSÃO}

Visualizando os cursos e materiais ofertados pelo programa em suas plataformas, observando com o olhar voltado a Educação do Campo, pode se perceber que o mesmo passa praticamente despercebido, com poucas menções e possibilidades. O uso de ferramentas digitais como carro chefe para as diversas possibilidades educacionais que estamos vivenciando, carece de que essa modalidade educacional seja contemplada com ofertas que vão ao encontro das realidades do Campo e dos educadores que trabalham neste contexto.

Novas abordagens foram grafadas devido a COVID-19, novos caminhos hão de ser seguidos dentro do meio educacional, e a partir do momento em que nos propormos a questionar as ofertas encontradas, tensionar e propor debates e questionamentos, projetando neles melhorias para o mesmo, poderemos, de alguma forma, contribuir para que os sujeitos afetados por essa possam ser contemplados de alguma forma.

Assim, cabe aqui, tensionar e apresentar esse programa, para que as demais modalidades de ensino que acabam ficando ofuscadas sejam lembradas, pensadas e contempladas.

\section{REFERÊNCIAS}

CALDART, Roseli Salete. Por Uma Educação do Campo: traços de uma identidade em construção. IN: KOLLING, Edgar Jorge; CERIOLI, Paulo Ricardo; CALDART, Roseli Salete. (org.). Educação do Campo: identidade e políticas públicas. Brasília, DF: articulação nacional Por Uma Educação do Campo, 2002. Coleção Por Uma Educação do Campo, n. 4.

CALDART, Roseli Salete. Trabalho Educação e Saúde, Rio de Janeiro, v. 7, n. 1, p. 35-64, mar.jun. 2009.

CALDART, Roseli Salete. A escola do campo em movimento. In: Por uma educação do campo. Rio de Janeiro: Vozes, 2011

CALDART, Roseli Salete. Educação do Campo. In: CALDART, Roseli Salete. PEREIRA, Isabel Brasil. ALENTEJANO, Paulo. FRIGOTTO, Gaudêncio (org.). Dicionário da Educação do Campo. Rio de Janeiro; São Paulo. Expressão Popular, 2012.

AVAMEC. Plataforma Educação Conectada. Disponível em: https://bit.ly/2M6Ao6m. Acessada em: 05 de junho de 2020 . 
REDMEC. Plataforma Educação Conectada. Disponível em: https://bit.ly/2LRmUeY. Acessada em: 05 de junho de 2020 .

PLATAFORMA. Programa Educação Conectada. Disponível em: https://bit.ly/3p60wNn. Acessada em: 05de junho de 2020. 